\title{
Rudolf Krauss, Giovanni Noe y una instantánea de las enfermedades infecciosas en el Chile de 1930
}

\author{
Walter Ledermann
}

\section{Rudolf Krauss, Giovanni Noe and a flash of infectious diseases in Chile, 1930}

When there were giants on the earth, two of them, Rudolf Kraus and Giovanni Noe, met at the ancient Bacteriological Institute of Chile, and founded together a journal representing the principles of the institution. A nostalgic glance over the papers published therein for these so named giants lets us know a little about the study of infectious diseases in the thirties, when tuberculosis and malaria were two of the biggest problems for the world's public health... then and now.

Key words: Rudolf Kraus, Giovanni Noe, Bacteriological Institute of Chile, malaria, tuberculosis.

Palabras clave: Rodolfo Kraus, Juan Noé, Instituto Bacteriológico de Chile, malaria, tuberculosis.
Centro de Estudios Humanistas Julio Prado, Santiago.

Recibido: 16 de marzo de 2015

Correspondencia a:

Walter Ledermann Dehnhardt oncemayor@gmail.com

\section{Kraus y Noe se encuentran y nace una revista}

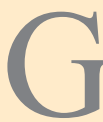
ratamente sorprendido, se admiraba un colega italiano al saber de la obra de su compatriota Giovanni Noe en Chile, sabio quien, como era costumbre en el pasado, tradujo su nombre al español y se llamó Juan. Curioso hábito éste, que llegó a extremos pintorescos como el de John Williams, marino inglés de nuestra Armada, famoso por tomar posesión del estrecho de Magallanes al mando de la fragata Ancud en 1843', quien se rebautizara primero como Juan Guillermos, cambiando a la vez de nombre y de apellido.

En aquellos días en que había gigantes sobre la Tierra, como cuenta la Biblia ${ }^{2}$ se juntaron Rudolf Kraus y Giovanni Noe (de aquí en adelante Rodolfo y Juan, como ellos mismos lo quisieron) y editaron una revista, pues desde que existen los científicos éstos forman sociedades, para crear acto seguido una publicación. Ocurrió el feliz nacimiento de la criatura gráfica en el año 1930, siendo bautizada como Revista del Instituto Bacteriológico de Chile, siendo a la vez, como reza su título, órgano de dicha institución y de la Sociedad Chilena de Microbiología e Higiene, cuyo Boletín llevaba anexo. Eran sus directores los mencionados Kraus y Noé; el secretario de redacción Eugenio Suárez, más tarde célebre -y férreo- Director del Instituto y Ministro de Salud; y redactores A. Demaría, C. Hurtado, O. Koref, E. Onetto, J. Orellana y S. del Río, este último muchísimo más famoso después que el mismo Suárez.

Revisando el primer año de la revista, llegamos a conocer los temas infectológicos que preocupaban, no sólo a estos dos sabios, sino a la comunidad médica de entonces, tuberculosis, malaria y tifus exantemático, que revisaremos por separado.

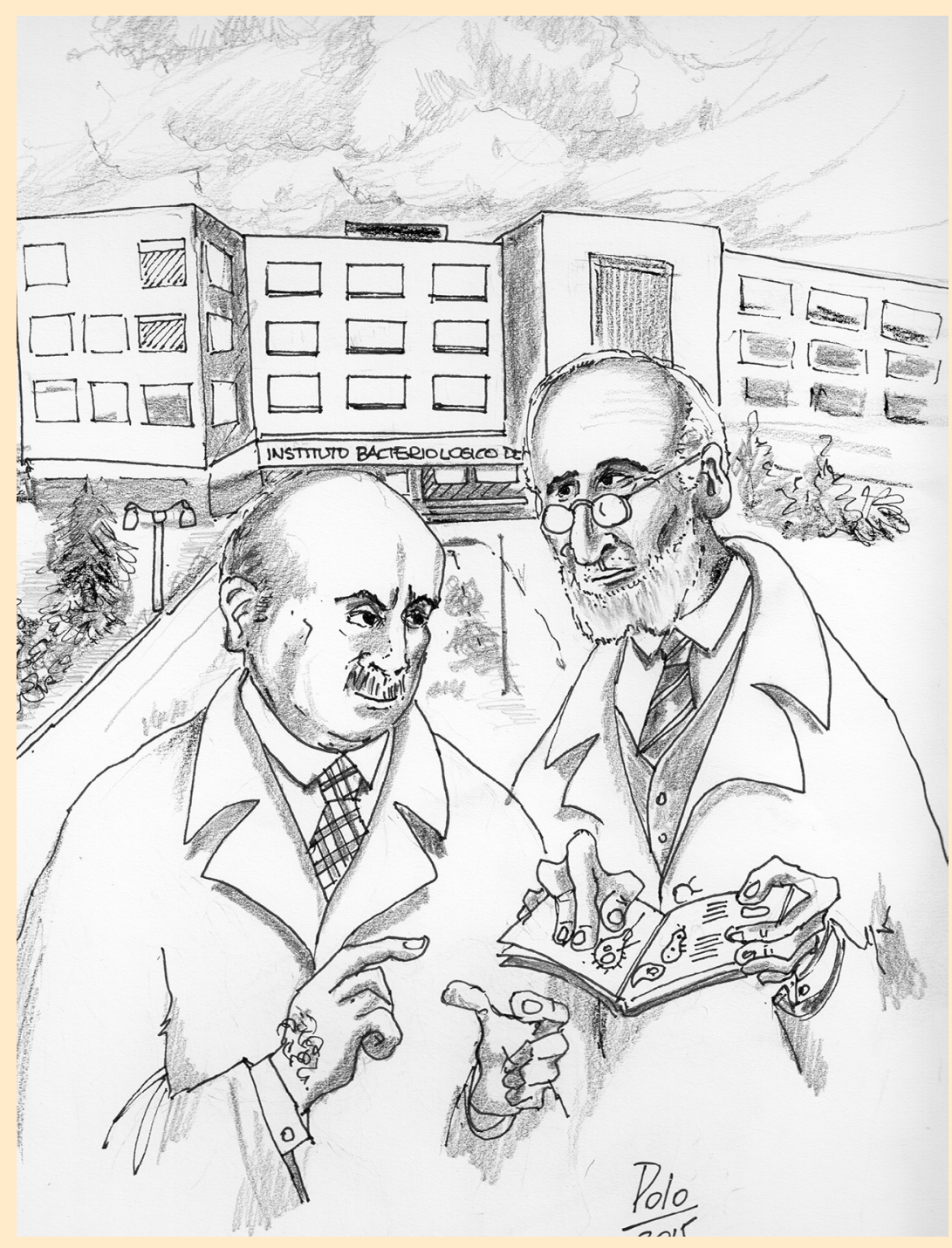

www.sochinf.cl 


\section{Tuberculosis: la cuestión del BCG}

En 1930, tras la muerte de un lactante vacunado en la Casa Nacional por Aníbal Ariztía y estando todavía no aclarado el desastre de Lübeck, en su doble carácter de director del Instituto Bacteriológico y Director de Sanidad, Kraus dispuso la suspensión provisoria de la vacunación con BCG en Chile. Recordemos brevemente que en la mencionada ciudad alemana 249 recién nacidos recibieron una vacuna BCG que no era tal, pues había sido erróneamente preparada con una cepa virulenta de Mycobacterium tuberculosis, falleciendo 73 de ellos ${ }^{3}$.

Aunque, como dijera el mismo Kraus, "la Comisión de Bacteriólogos en la Conferencia Internacional de París, dedicada al estudio de la vacunación preventiva por el BCG, llegó por unanimidad a la conclusión que el BCG constituye una vacuna inofensiva y no produce tuberculosis evolutiva" y que "la Comisión Clínica afirmó que el BCG administrado per os en recién nacidos hasta el décimo día de vida, y subcutáneamente en los que han pasado esa edad y en los adultos, no es capaz de producir tuberculosis", el triste caso de este niño hizo renacer todas sus dudas, al punto de tomar tan drástica resolución ${ }^{4}$.

En la quinta sesión de la Sociedad Chilena de Microbiología e Higiene, el 4 de agosto de 1930, bajo la presidencia del mismo Kraus, el profesor Ariztía presentó dos casos de lactantes de la Casa Nacional vacunados con BCG, uno de los cuales era el fallecido, de tres meses de edad y afectado de una peritonitis tuberculosa, con adenopatías abdominales y sub-diafragmáticas. El doctor Orellana, del I. Bacteriológico, describió los cultivos y las pruebas hechas con el bacilo, que lo sindicarían como un Mycobacterium bovis, es decir, de la misma especie que la cepa vaccinal, en tanto que el doctor Sótero del Río manifestó que su estudio histológico de las lesiones indicaba que se trataba de una tuberculosis activa.

El profesor Debré defendió la vacuna diciendo que el caso presentado por el profesor Ariztía "no demostraba gran cosa, siendo imposible probar que el niño no pudo haberse contagiado, máxime cuando el Dr. Ariztía dice haberse descubierto entre las enfermeras un caso de tuberculosis renal"'.

Entrando al terreno anecdótico, el profesor Ariztía rechazaría el BCG hasta sus últimos días, conducta que en el Hospital Luis Calvo Mackenna compartirían algunos de sus más leales discípulos. En más de una ocasión nos advirtió, a quienes fuéramos sus alumnos, de la siniestra posibilidad de una reversión de la cepa "inocua" a una "patógena", así como de su dudosa efectividad, juicio en el que no estaba solo pues hasta hoy persiste esta duda y se sigue buscando algo mejor; también se quejaba que al vacunar a los recién nacidos se perdía el gran valor diagnóstico del PPD.

En cuanto a Kraus, sus dudas estaban insertas en la eterna controversia germano-francesa en el campo de la tuberculosis y, como buen austriaco, adhería a la escuela alemana. Sostenía que en sus trabajos fundamentales Calmette y Guérin aseguraban siempre que "el tipo BCG" estaba hereditariamente fijado en su atenuación y no produce lesiones patológicas algunas en animales sensibles, aun cuando se aplica en grandes cantidades, y que protege contra la infección tuberculosa. Con esto, decía Kraus que se ponía Calmette en oposición a la teoría vigente en esos tiempos, basada en los trabajos de Koch, de Roemer y de Hamburger; así como del propio Kraus y de Volk $^{6-8}$, que dieran origen a la Infektionsimmunitaet de la escuela alemana, una inmunidad especial para la tuberculosis, que no se produce ni por microbios muertos, ni en la tuberculosis curada, sino a consecuencia de las lesiones manifiestas tuberculosis. Sin embargo, como la cepa BCG producía lesiones tuberculosas, pero no progresivas, no era nosógena sino, por el contrario, inocua. Bajo estos supuestos aceptó y adoptó Kraus las recomendaciones internacionales para su uso.

Pero ahora, con los accidentes de Lübeck y de la Casa Nacional, sus dudas volvían con fuerza y le venían a la mente los trabajos del húngaro V. Hutyra y del uruguayo Estenio Hormaeche, que mostraban cómo el BCG, bajo ciertas condiciones, dentro del organismo, puede sufrir una exaltación parcial de su virulencia y hacerse muy patógeno y nosógeno para cuyes, menos para los conejos y no para los terneros.

Del primero dice Kraus que era de Budapest y un autor de gran reputación; a Hormaeche lo conocía personalmente, tanto que le pidió las cepas de Streptococcus y de BCG con virulencia aumentada que había utilizado en sus experiencias, consistentes en inocular con 25 a 50 mgr de BCG a dos grupos distintos de cobayos, uno con animales previamente infectados con Streptococcus, que desarrollaban luego una diseminación del BCG, y otro con animales sanos, en quienes este fenómeno no se presentaba. En cuanto a los trabajos del húngaro, éstos mostraban que con el clima frío, en invierno, el BCG era capaz de causar diseminación en cobayos y conejos, pero no en terneros.

Cuando su artículo estaba ya en prensa, recibió Kraus noticias tranquilizadoras sobre lo ocurrido en Lübeck, logrando agregar al pie una nota en letra chica, que pasamos a transcribir:

"En una conferencia publicada en "La Presse Médicale" el 26 de julio de 1930, asegura Calmette que en lugar de la vacuna BCG, fue administrado un cultivo humano virulento. Datos oficiales de Alemania, que hemos pedido desde la Dirección General de Sanidad cablegráficamente, dicen lo siguiente (16-IX-30: El Ministerio del Interior confirma que la vacuna entregada Laboratorio Estado, pura y en perfectas condiciones. Hay probabilidad muy lejana bacilos por sí mismos convertídose infecciosos, pero todo 
manifiesta descuido, error Lübeck. Entre 250 vacunados, fallecidos 72 y existen 55 enfermos. Director General de Sanidad mantiene por prudencia recomendación instituciones médicas alemanas no usar vacuna mientras investigación no establezca responsabilidad definitivamente. Envío original comunicación oficial.- Zañartu".

Hacia fines de año, confirmado el "error Lübeck", Kraus sugirió al ministro levantar la prohibición, pero solían decir algunos de quienes fueron sus contemporáneos en el Instituto Bacteriológico, le quedó para siempre, como reza la película de Hitchcock, la sombra de una duda...

\section{La porfiada malaria}

Revisando la situación sanitaria del país, dice Kraus que casi un tercio de la mortalidad se debe a enfermedades infecciosas de la primera infancia, que sitúa en el primer año de vida y que era causada mayoritariamente por tuberculosis, poniendo a continuación difteria, escarlatina, sarampión, tos convulsiva, tifoidea, carbunclo, rabia, etc. No menciona la malaria, quizás porque estaba circunscrita a una delimitada región, pero agrega luego que el programa sanitario futuro incluye la campaña contra el paludismo en el Norte, la lucha contra la anquilostomiasis en las minas y el combate contra la equinococosis ${ }^{9}$.

El control de la malaria fue obra de Juan Noé, cuyos primeros trabajos datan de 1913, ocasión en que describió como único vector al Anopheles pseudopunctipennis, continuando en la época plebiscitaria, (llamada así en referencia al plebiscito de 1925 para resolver la soberanía de Tacna y Arica) con su participación en la comisión designada con fines profilácticos. Hacia 1930 encabezó otra comisión, esta vez "de estudio" enviada al norte por el Ministerio de Relaciones Exteriores... iEsto si es novedad! ¿Qué tenía que ver este Ministerio con la salud? Mucho, pues la malaria atacaba tanto a chilenos como peruanos, que se estaban reubicando en Tacna y Arica de acuerdo a sus sentimientos nacionalistas, de manera que la situación sanitaria chilena afectaba también a Perú. Ninguna novedad, en cambio, es la "fiebre de las comisiones", enfermedad endémica en Chile, más persistente que la fiebre tifoidea.

En fin, fuese como fuese, uno de los frutos del trabajo de la mentada comisión fue el estudio de los Índices Epidemiológicos, así, con mayúsculas, publicado el mismo año 30 por R. Páez, cuyo nombre de pila, así como su profesión y su grado académico ignoramos, sabiendo sólo que era "ayudante en el Anexo de Parasitología que el profesor Noé dirigía en el Instituto Bacteriológico ${ }^{10}$.

Hasta la fecha -comienza diciendo Páez- no se ha podido realizar en Chile un estudio epidemiológico completo del paludismo. Circunstancias diversas, como la lejanía de la zona palustre de los centros de estudio y el escaso dinero puesto a disposición de las comisiones, han obligado a realizar las investigaciones en forma rápida, por cortos periodos y separadas unas de otras por intervalos de algunos años.

Cuatro eran los índices que estudió la comisión:

1. Índice esplénico, consistente en evaluar el volumen medio del bazo y el porcentaje de esplenomegalias en la población.

2. Índice plasmódico: investigación de parásitos en la sangre de los enfermos.

3. Índice anófelo-intestinal: porcentaje de mosquitos infectados por los parásitos en la pared intestinal.

4. Índice anófelo-salival: porcentaje de mosquitos infectados por esporozoitos en sus glándulas salivales.

Intentemos imaginar las condiciones en que trabajaban estos intrépidos investigadores hace ya casi un siglo, para encontrar y estudiar 112 niños reunidos al azar, en su mayor parte escolares en los valles de Azapa y de Lluta, con hipertrofia esplénica. Se queja el ayudante Páez de la lejanía de la zona palustre, de los centros de estudios y del escaso dinero puesto a disposición de las comisiones, pero igual viaja por zonas desoladas en algún vehículo rudimentario, llevando a cuestas un pesado "baúl de campaña", como el que una vez encontramos en una bodeguita de la Dirección del IBCH, provisto de jeringas, tubos de ensayo, alcohol, yodo, vendas, reactivos diversos, sin que pudiéramos rescatarlo para algún museo médico. Y todo para llegar a unos modestos y sorprendentes resultados, una discordancia entre los índices anófelointestinal y esplénico, que Noé, el poder tras el trono en esta investigación, intenta explicar por la presencia en un valle de mucha población de gente negra y mulata, a la cual atribuye cierta refractariedad al paludismo. Debe tomarse en cuenta también -continúa escribiendo Páezque la cantidad de zancudos domésticos (índice anofélico) es verdaderamente enorme... hemos podido, sin gran esfuerzo, cazar en una pieza de un rancho en el valle de Lluta, durante dos horas, alrededor de 400 zancudos...

Se descubriría posteriormente que algunos nativos de África Occidental, negativos para el grupo hemático Duffy, son resistentes al Plasmodium vivax, por deficiencia o ausencia de un receptor de membrana (factor Duffy) para los merozoitos del plasmodio, de manera que no estaba descaminado el profesor Noé en cuanto a la gente negra y mulata. En cuanto a los distintos índices del estudio, poco se los menciona en la actualidad.

Pasarían quince años, hasta 1945, para que el triunfo de Noé sobre la malaria se consolidara: desde entonces no se registran casos autóctonos en Chile ${ }^{12}$. De este gran investigador italiano ya está todo dicho; para su biografía, nada mejor que el relato que ha hecho su hija ${ }^{12}$. 


\section{Discusión y hallazgo de la Bartonella muris}

Pero en 1930 Noé estaba enfrascado en otras varias investigaciones, una de ella sobre la Bartonella, enigmático microorganismo al que finalmente aceptó como bacteria, habiendo aislado en ese año las primeras cepas de la especie Bartonella muris en Chile. Pletórico de entusiasmo, hace esta fascinante descripción de ella: En las observaciones al ultramiscroscopio, los individuos de Bartonella aparecen moviéndose con gran rapidez, mientras los autores hablan sólo de cierta movilidad. Se les ve atravesar velozmente el campo ópticamente vacio del hematie, y chocar violentamente contra la superficie externa, retrayéndose luego con gran rapidez... ${ }^{13}$. En el mismo artículo una cuestión muy interesante (que) ponia el Profesor Kraus hace unos dias en una conversación que tuvimos acerca de las Bartonellas... ¿será B. muris una especie verdaderamente distinta de la B. bacilliformis?

Imaginemos a los dos sabios discutiendo, al atardecer, en uno de los patios. ¿Recurrirían, el austriaco y el italiano, al castellano como idioma común?

-- ¡Ma, che cosa, dice Kraus! Veramente que son due especies distintas.

-- Rein unmöglich... En modo alguno posible. Das nämliche, ja, vea como se mueven, como son lesiones pulmonares en cuyes. ¡Nein, nein, das läuft auf dasselbe hinaus!

-- Professore, pero las lesiones hepáticas son tutti differente... Y, sea gentile, e no parlare en tudesco, per favore.

No sabemos cómo terminó la discusión sobre el tema, ni sabemos si la cepa encontrada por Noé era B. muris, una de las más de 25 especies del género descritas hasta ahora, aunque no involucrada claramente en patología humana; y si hemos citado el artículo ha sido sólo para mostrar los múltiples intereses de ambos personajes.

\section{Kraus, von Pettenkofer y las pettenkofereas}

Es increíble -nos contó un sábado en la mañana Mario Prado LeFort, cuando habíamos terminado de preparar la semilla para la vacuna pertussis y se había levantado la orden de silencio- cómo en tanto poco tiempo entre nosotros, apenas tres años, dejara Kraus huella tan honda. Quizás la explicación esté en esa combinación de carisma, seriedad y orden, que le permitió sistematizar las confusas ideas que comandaban nuestro entusiasmo. Todo lo organizó, todo lo aclaró y mucho previó. Tanto influyó en nosotros, que más de alguno se apartó de la microbiología francesa y se acercó a la germánica, al extremo que Carlos Garcés, al descubrir las que después se llamarian "formas L", descubrimiento que, en su modestia, no se atrevió a publicar, las denominó "petenkofereas" en honor a Max von Pettenkofer, una suerte de idolo de Kraus.
Buscando una corroboración de estas afirmaciones, encontramos estas palabras de Kraus, al analizar el estado sanitario de Chile: Fue Max von Pettenkofer, en Alemania, quien llevó la higiene a la altura de una ciencia exacta; analizando, contando, midiendo y pesando los factores externos de los cuales depende la salud. Y eso fue lo que hizo el sabio austriaco para organizar, no sólo en Instituto recién creado, sino la salud pública de la joven república: analizar, contar, medir y pesar, para meter en la horma la desbocada inspiración latina.

Kraus tuvo largas discusiones con Calmette -nos contaba Prado Le Fort- sobre la inmunidad del BCG, en ocasiones asesorado por von Pettenkofer, mientras Eugenio Suárez, más tarde Director del IBCH, representaba al francés. Al final, Calmette se rindió y terminó por concordar, al menos en parte, con la tesis germánica. La confirmación de este relato la da el mismo Kraus: Después de una larga discusión con Calmette, pudimos resumir, en ocasión de una conferencia de la Sociedad Microbiológica en Viena, 1927, a la cual asistió en Dr. Suárez en nombre de Calmette, que el BCG produce lesiones tuberculosas, pero que no son progresivas y que después de 6 a 8 semanas empezaban a desaparecer, hasta su completa curación...

Aquella mañana sabatina nuestro mentor, tras llevar a la estufa los tubos con la Bordetella recién sembrada, permaneció un rato abstraído, sonrió y dijo: Era dificil discutir sobre vacunas con el profesor Kraus, pues sabia de ellas como ninguno y la inmunología era su fuerte. Tenía mucho interés en lograr una vacuna efectiva contra el cólera; contaba que a principios de siglo, 1908 o 1910, lo habian enviado a Rusia, creo que a San Petersburgo, para ayudar en una epidemia de cólera, y que antes de partir tuvo largas conversaciones con von Pettenkofer, porque, en sus palabras, "no podía ir allá como burro completo".

La hegemonía de la escuela germánica en la microbiología institutana duró poco tras la muerte del Kraus, pues los directores siguientes, Eugenio Suárez y Eduardo Dussert eran, especialmente el último, admiradores de la escuela francesa. El austriaco se vino tempranamente a América del Sur, anticipándose al inicio de la guerra del 14, que con buen ojo previó. Estuvo en el Instituto Butantan, en Brasil, y en 1921 estaba dirigiendo el Instituto de Bacteriología de Buenos Aires, Argentina, donde estuvo muy poco, pues tres años después, dando un paso equivocado, creyó que en Europa la situación mejoraba y retorno a su patria. Más, las cosas no marchaban del todo bien en el Instituto de Seroterapia: no eran, contaba Dussert, los mismos tiempos en que iniciara su carrera en plena juventud, a poco de titularse, y por eso no vaciló en venir a meterse aquí, pero la vida no le alcanzó para mucho, aunque fue harto lo que hizo en unos tres años, considerando que su especialidad era el cólera y aqui 
no tenemos esa payasada. Y, brotándole, como siempre, el amor a la France, agregaba que al fin y al cabo, más aprendió a su breve paso por el Institute Pasteur que en todos sus años en Viena.

En cuanto a las pettenkofereas, esa es otra historia, como diría Kipling, que quizás narremos en algún hipotético futuro.

\section{Azarosa existencia de la Revista y del Boletín que la siguió}

La revista tuvo una vida azarosa y breve, porque así fue la vida de Rudolf Kraus, fallecido prematuramente a los 63 años en 1932, y porque la conexión de Giovanni Noe con el Instituto era muy laxa: siendo el italiano un parasitólogo de tomo y lomo, sus intereses se fueron separando de la bacteriología, que era la esencia del establecimiento, y la muerte del alemán influyó decisivamente en su alejamiento. Así las cosas, la revista se extinguió hacia fines de los años treintas, no sin dar antes fuertes pataleos por sobrevivir, siendo reemplazada como órgano de expresión de la institución por un más modesto Boletín en 1942.

El Boletín del Instituto Bacteriológico de Chile se publicó, hasta donde hemos podido averiguar excavando cadáveres impresos de diversas bodegas del Instituto, entre el volumen 1 de 1942 y el 11 de 1959, debiendo tres veces recurrir los editores al subterfugio de publicar dos años en uno para mantener la continuidad: 1944/1945 en el volumen 3, 1946/1947 en el volumen 4, y 1957/1958 para el volumen 10. Extinguido en 1959, resucitó en 1970, gracias a la voluntad de Mario Miranda, designado Director del Instituto en 1970 para darle un impulso renovador, pero la publicación y el Director tuvieron destinos bien diferentes, pues el nuevo Boletín, que partió como volumen 12, duró hasta 1978 con el volumen 20, en tanto que Miranda, muy inquieto por la situación política que vivía el país, dejó su cargo en 1971, lo retomó en 1972 y se fue al extranjero el mismo año, dejando la papa caliente, esto es, institución y publicación, en nuestras juveniles e inexpertas manos.

En 1980 murió el antiguo Instituto Bacteriológico de Chile, para dar nacimiento al Instituto de Salud Pública de Chile (ISP), y la publicación cambió de nombre una vez más, apareciendo el volumen 21 como Boletín del ISP. En ese momento dejamos institución y publicación, como antes lo hiciera Miranda, comprendiendo que los intereses, los deberes y el quehacer del ISP eran por completo diferentes: más que todo, había cambiado el espíritu de los institutanos, aquél que heredáramos de los gigantes, que fuéramos incapaces de mantener a su altura y que diecisiete años de dirección militar -y no científica- terminara por demoler.

El Boletín del ISP duró, o se arrastró, hasta fines de los ochentas: el último que nos llegara es el volumen 27, de los años 1987/1988. Entonces, o poco después, y de acuerdo a su nueva filosofía, el ISP lo reemplazó por publicaciones técnicas, destinadas a los laboratorios de la red pública.

Y ya no hubo gigantes sobre la Tierra. En realidad -sacudiéndonos la nostalgia del recuerdo, que nos hace exagerar- quizás nunca los hubo y hablar de ellos es una exageración; en los años treinta eran frecuentes los sabios que dominaban varias especialidades de la medicina; hoy en día, con el vertiginoso avance del conocimiento, es inevitable no especializarse en parcelas del saber cada vez más pequeñas.

\section{Resumen}

Cuando había gigantes sobre la Tierra, dos de ellos, Rodolfo Kraus y Juan Noé, austriaco el uno e italiano el otro, coincidieron por un tiempo en el antiguo Instituto Bacteriológico de Chile. Tuvieron entonces la idea de crear una revista que representara los fines de la institución y el progreso de la microbiología. Una mirada nostálgica sobre los artículos publicados en dicha revista, nos permite saber un poco sobre el estudio de las enfermedades infecciosas en los años treinta, cuando la tuberculosis y la malaria eran dos de los mayores problemas para salud pública en el mundo... entonces y ahora.

\section{Referencias bibliográficas}

1.- Anrique R, Nicolás. Diario de la goleta Ancud al mando del capitán de fragata Juan Guillermos (1843) para tomar posesión del Estrecho de Magallanes. Imprenta, Litografía i Encuadernación Barcelona, Santiago de Chile 1901.

2.- Génesis 6:4. Y habia gigantes en la Tierra en aquellos dias, y también después, cuando los hijos de Dios se unieron a las hijas de los hombres y ellas dieron luz a hijos. Estos son los héroes de la antigüedad, hombres de renombre.

3.- Laval E. Sobre la transmisión de la tuberculosis y los primeros ensayos del BCG. Rev Chil Infectol Edición aniversario 2003; 51-3.

4.- Kraus R. Sobre la inocuidad de la vacuna BCG. Rev Inst Bacteriol 1930; 1 (4): 35-40.

5.- Boletín de la Sociedad Chilena de Microbiología e Higiene, quinta sesión, 4 de agosto de 1930; pp. 4-5. Adosado a: Rev Inst Bacteriol 1930; 1 (4).

6.- Kraus R, Hofer G. Dtsch Med Wochenschr 1912; 38: 1227-35.

7.- Kraus R, Hofer G. Wien Klin Wochenschr 1921; 25: IIII.

8.- Kraus R, Löwenstein E, Volk R. Dtsch Med Wochenschr 1914; 3: 389-402.

9.- Kraus R. El estado sanitario del país y la sanidad nacional. Rev Inst Bacteriol 1930; 1 (4): 67-75.

10.- Páez R. Índices epidemiológicos de la malaria en el Departamento de Arica. Rev Inst Bacteriol 1930; 1 (4): 41-8.

11.- Schenone H, Olea N, Rojas S, García D. Malaria en Chile: 1913-2001. Rev Med Chile 2002; 130 (10): 1170-6.

12.- Noé Pizzo A. Juan Noé. Un testimonio familiar sobre su vida y obra. Ediciones de la Universidad de Chile 1987.

13.- Noe J, Páez R. La Bartonella muris en Chile. Rev Inst Bacterial Chile 1930; I (4): 20-7. 